\title{
-Originals-
}

\section{Bupivacaine combined with isoflurane synergistically depressed myocardial contractility in rat working heart preparation}

\author{
Takero Takamura, Atsuhiro Sakamoto and Ryo Ogawa \\ Department of Anesthesiology, Nippon Medical School
}

\begin{abstract}
It is well known that both local and volatile anesthetics depress myocardial functions. This study was performed to evaluate the combined effects of commonly utilized local anesthetics (bupivacaine, mepivacaine, and lidocaine) and a volatile anesthetic (isoflurane) on heart rate and myocardial contractility in an isolated rat working heart preparation using each local anesthetic at 0 to $3 \times 10^{-4}(\mathrm{~mol} / \mathrm{L})$ with or without $1 \mathrm{MAC}$ (minimum alveolar concentration) of isoflurane. The three local anesthetics depressed the heart rate and myocardial contractility dose-dependently. Bupivacaine depressed the heart rate more than the other two local anesthetics. One MAC isoflurane showed significant negative inotropic effects, and accelerated the effects of the local anesthetics. By using isobolographic analysis, we concluded that the combined effect of isoflurane and bupivacaine on myocardial negative inotropism was synergistic, while the effects of isoflurane and mepivacaine or lidocaine were additive. (J Nippon Med Sch 1997; $64: 292-297$ )
\end{abstract}

Key words: rat working heart, bupivacaine, isoflurane, myocardial functions, synergistic effect

\section{Introduction}

A high plasma concentration of bupivacaine is cardiotoxic. The toxicity of bupivacaine and lidocaine has been examined in animal preparations ${ }^{1-4}$. It has also been suggested that volatile anesthetics, including isoflurane, depress myocardial functions ${ }^{5-11}$.

Recently, regional anesthesia has been utilized to anesthetize patients in combination with general anesthesia, and it is possible that local anesthetic intoxication will occur during general anesthesia. However, the effects of the combination of two kinds of anesthetics have not been clarified. We investigated the combined effects of isoflurane and commonly utilized local anesthetics on heart rate and myocardial contractility in a working rat heart preparation.

\section{Materials and Methods}

The ethical committee on animal study at Nippon Medical School approved the experimental design.

Thirty male Sprague-Dawley rats each weighing 280-300 g were anesthetized with sodium pentobarbital $50 \mathrm{mg} / \mathrm{kg}$ given ip. The heart was excised and immersed in ice-cold Krebs-Henseleit bicarbonate buffer (KHB) solution, consisting in $\mathrm{mmol} / \mathrm{ml}$ of $\mathrm{NaCl} 118, \mathrm{KCl} 4.7, \mathrm{CaCl}_{2} 1.25, \mathrm{MgSO}_{4} 1.25, \mathrm{KH}_{2}$ $\mathrm{PO}_{4} 1.25, \mathrm{NaHCO}_{3} 24$, and glucose 15, equilibrated with $95 \%$ oxygen and $5 \%$ carbon dioxide. An isolated heart perfusion apparatus (K-884600, Kontes, New Jersey, USA) was used to perfuse the rat heart ${ }^{12}$. The aorta was cannulated and $37^{\circ} \mathrm{C}$-KHB solution was perfused according to the Langendorff procedure. The atrium was cannulated via the pulmonary vein within $5 \mathrm{~min}$ of retrograde perfusion.

Correspondence to Takero Takamura, Department of Anesthesiology, Nippon Medical School Hospital, 1-1-5

Sendagi, Bunkyo-ku, Tokyo 113, Japan 
The Langendorff mode was then converted to a working heart mode by switching the supply of perfusate from the aorta to the left atrial cannulation (filling pressure: $15 \mathrm{~cm} \mathrm{H}_{2} \mathrm{O}$ ). Under this procedure, the left ventricle began spontaneously to eject the perfusate through the aortic cannula against the residence made by a fine tube.

The hearts were randomly assigned to six groups; three local anesthetic group [bupivacaine $(n=5)$, mepivacaine $(n=5)$, lidocaine $(n=5)]$, and three isoflurane added groups [isoflurane plus bupivacaine $(n=5)$, isoflurane plus mepivacaine $(n=5)$, and isoflurane plus lidocaine $(\mathrm{n}=5)]$.

In the local anesthetic groups, local anesthetic was added to the perfusate at concentrations of $10^{-6}, 3 \times 10^{-6}, 10^{-5}, 3 \times 10^{-5}, 10^{-4}$, and $3 \times 10^{-4}$ $(\mathrm{mol} / \mathrm{L})$ at intervals of $5 \mathrm{~min}$ after a stabilization period of $20 \mathrm{~min}$. In each isoflurane added group, 1 MAC concentration of isoflurane was bubbled into the KHB solution through a calibrated vaporizer. The hearts were perfused for 10 min with a solution containing isoflurane after a stabilization period of $10 \mathrm{~min}$, after which, local anesthetics were added in the manner described above.

A needle type cannula ( $23 \mathrm{G}$ ) was placed in the left ventricular cavity transmurally and was connected to a transducer (Blood Pressure Amplifier AP-641 G, Nihon Kohden, Tokyo, Japan) and a pressure processor (EQ-601 G, Nihon Kohden, Tokyo, Japan). The pressure waves were differentiated by computer. Heart rate (HR: bpm), left ventricular pressure (LVP: $\mathrm{mmHg}$ ) and peaks in differentiation of LVP by time (dp/dt max: $\mathrm{mmHg} / \mathrm{sec}$ ) were recorded at the control period, $10 \mathrm{~min}$ after exposure to isoflurane, and every 5 min after the administration of local anesthetics.

To determine whether the depression of myocardial function by the combination of isoflurane and local anesthetics is additive or synergistic, isobolographic analysis was performed according to the method of Tallarida et $\mathrm{al}^{13}$. The theoretical concentration of local anesthetics and of bubbled isoflurane which reduced $\mathrm{dp} / \mathrm{dt}$ max to $50 \%$ of the control $\left(\mathrm{ED}_{50}\right)$, as well as theoretical 95\% confidence intervals (CIS), were computed ${ }^{13}$. The effects of isoflurane at concentrations of 1.5, 2.0, 2.5, 3.0, 3.5, 4.0, and 4.5 MAC on the same isolated rat working heart preparation were also measured to obtain the theoretical $\mathrm{ED}_{50}$ value of isoflurane. The theoretical $\mathrm{ED}_{50} \mathrm{~s}$ were then plotted on $\mathrm{X}$ and $\mathrm{Y}$ axes, and the diagonal were drawn between two theoretical $\mathrm{ED}_{50} \mathrm{~S}$ lines regarded as the theoretical additive line. When the points experimentally obtained fell below the theoretical additive line, the points indicated the synergistic action on the myocardium.

The values were represented by mathematical means and central tendency by standard deviations. The comparisons of means among the three groups were performed using one-way ANOVA. Fisher's PLSD test was applied to assess differences between two groups if ANOVA denied the uniformity of means. A p-value under 5\% was considered significant.

\section{Results}

There were no significant differences in the values obtained in the control period among the six groups.

Fig. 1 shows the concentrations of local anesthetics which stopped the spontaneous contraction of heart preparations. In the preparations which were not exposed to volatile anesthetic agents, the concentrations decreased from lidocaine, mepivacaine to bupivacaine. There was a 30 -fold difference between lidocaine and bupivacaine. Similar results were obtained in the preparations exposed to local anesthetics combined with isoflurane. However, the trend for the concentration of local anesthetics to cause cardiac standstill was lower in the groups with isoflurane than in the groups without isoflurane (Fig. 1).

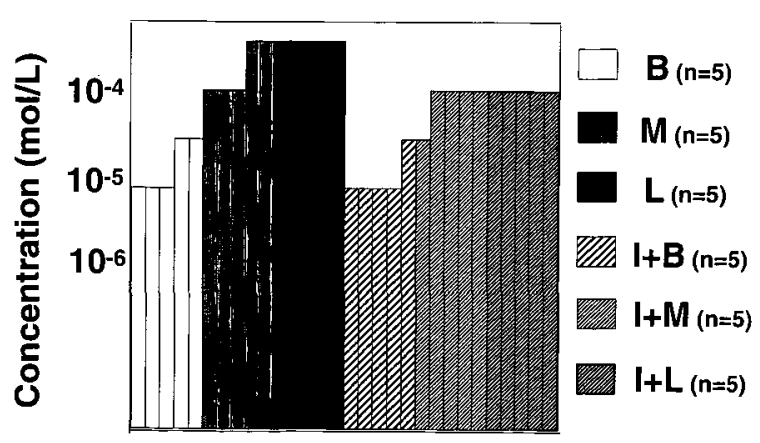

Fig. 1 Concentrations of local anesthetics which stopped spontaneous contraction of heart preparations (all samples). B: bupivacaine, M: mepivacaine, L: lidocaine, I: isoflurane, Concentration: concentration of local anesthetics. 
Three local anesthetics decreased heart rate dosedependently without isoflurane (Fig. 2 above). The heart rate in the bupivacaine group was reduced significantly compared to the lidocaine group at $10^{-5}$ and $3 \times 10^{-5} \mathrm{~mol} / \mathrm{L}$. Also the heart rate in the mepivacaine group was reduced significantly compared to the lidocaine group at $3 \times 10^{-4} \mathrm{~mol} / \mathrm{L}$. No change in heart rate was observed when isoflurane was added to the perfusate, and similar changes in heart rate were observed among the three groups with local anesthetics and isoflurane (Fig. 2 below).
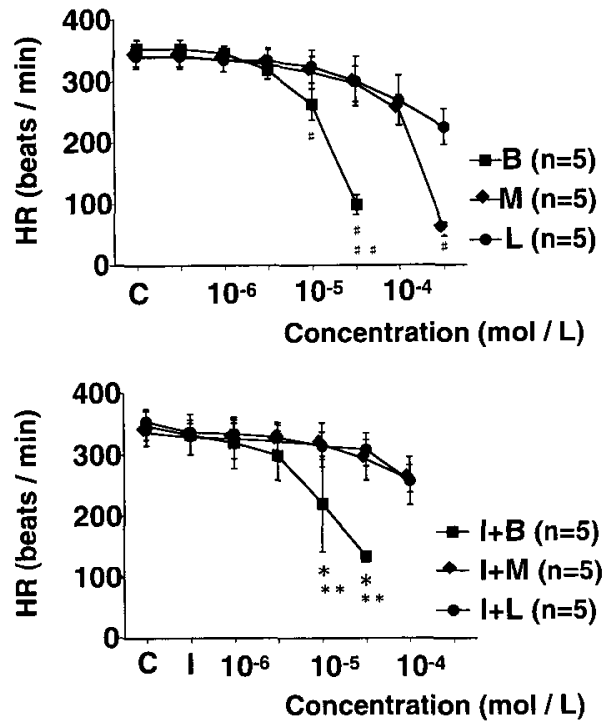

Fig. 2 Effect of local anesthetics on heart rate with isoflurane (below) and without isoflurane (above) (mean $\pm \mathrm{SE}$ ). B: bupivacaine, $\mathrm{M}$ : mepivacaine, $\mathrm{L}$ : lidocaine, $\mathrm{I}$ : isoflurance, C: control time, (I) The time when isoflurane exposure was started, Concentration: concentration of local anesthetics, HR: heart rate. $\# \mathrm{P}<0.05$ vs lidocaine; \# $\mathrm{P}<$ 0.05 vs mepivacaine, ${ }^{*} \mathrm{P}<0.05$ vs isoflurane plus lidocaine; ${ }^{* *} \mathrm{P}<0.05$ vs isoflurane plus mepivacaine.
There was no significant difference in heart rate between the local anesthetics with or without isoflurane. No premature contraction was observed in any of the six groups until just before cardiac standstill.

The values of $\mathrm{dp} / \mathrm{dt}$ max decreased in parallel to the concentration of isoflurane bubbled into the perfusate, and the theoretical $\mathrm{ED}_{50}$ was 2.73 $\mathrm{MAC}$ (95\% CIS: 2.70-2.79) (Table 1). At $1 \mathrm{MAC}$ isoflurane depressed $\mathrm{dp} / \mathrm{dt}$ max from $4066 \pm 274(\mathrm{mmHg} / \mathrm{sec})$ to $3566 \pm 349(\mathrm{mmHg} / \mathrm{sec})$ (the average of the three local anesthetic groups) significantly (Fig. 3 below, Fig. 4). Local anesthetics reduced cardiac contractility dose-dependently; however, there was no significant difference between the three local anesthetics (Fig. 3 above), even though the theoretical $\mathrm{ED}_{50}$ and $95 \%$ CIS were different among the three local anesthetics (Table 1).

Isoflurane accelerated the reduction of myocar. dial contractility. There was a significant difference between the groups with and without isoflurane at any concentration of the three local anesthetics (Fig. 4). Bupivacaine at a concentration of $3 \times 10^{-5}$ $\mathrm{mol} / \mathrm{L}$ with isoflurane showed a significantly lower $\mathrm{dp} / \mathrm{dt}$ max than mepivacaine or lidocaine with isoflurane (Fig. 3). The theoretical $\mathrm{ED}_{50}$ of bupivacaine with isoflurane was markedly lower than bupivacaine alone; however, there was no marked difference between the mepivacaine and lidocaine groups with and without isoflurane (Table 1).

Isobolographic analysis revealed that bupivacaine had a synergistic negative inotropic effect in combination with isoflurane, and lidocaine and mepivacaine had additive negative inotropic effects on the myocardium (Fig. 5).

Table 1 The ED 50 values and 95\% confidence intervals of negative inotropic effects of three local anesthetics, isoflurane, and the local anesthetics in combination with isofurane

\begin{tabular}{l|rlll}
\hline & $\mathrm{n}$ & \multicolumn{1}{c}{ ED 50 } & \multicolumn{2}{c}{$95 \%$ CIS } \\
\hline B & 5 & $1.15 \times 10^{-4}$ & $8.13 \times 10^{-5}-1.90 \times 10^{-4}$ & $(\mathrm{~mol} / \mathrm{L})$ \\
$\mathrm{M}$ & 5 & $3.39 \times 10^{-4}$ & $2.30 \times 10^{-5}-8.10 \times 10^{-4}$ & $(\mathrm{~mol} / \mathrm{L})$ \\
$\mathrm{L}$ & 5 & $2.00 \times 10^{-3}$ & $1.00 \times 10^{-3}-7.20 \times 10^{-3}$ & $(\mathrm{~mol} / \mathrm{L})$ \\
$\mathrm{B}+\mathrm{I}$ & 5 & $1.95 \times 10^{-5}$ & $1.41 \times 10^{-5}-6.03 \times 10^{-5}$ & $(\mathrm{~mol} / \mathrm{L})$ \\
$\mathrm{M}+\mathrm{I}$ & 5 & $3.98 \times 10^{-4}$ & $2.75 \times 10^{-4}-6.60 \times 10^{-4}$ & $(\mathrm{~mol} / \mathrm{L})$ \\
$\mathrm{L}+\mathrm{I}$ & 5 & $2.95 \times 10^{-3}$ & $1.31 \times 10^{-3}-9.80 \times 10^{-3}$ & $(\mathrm{~mol} / \mathrm{L})$ \\
$\mathrm{I}$ & 15 & 2.73 & $2.70-2.79$ & $(\mathrm{MAC})$ \\
\hline
\end{tabular}

$\mathrm{B}$ : bupivacaine, $\mathrm{M}$ : mepivacaine, $\mathrm{L}$ : lidocaine, I : isoflurane. 

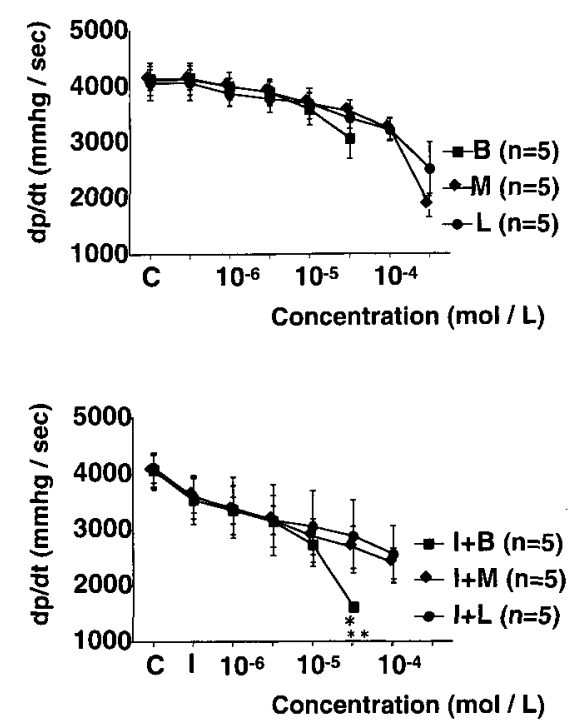

Fig. 3 Effect of local anesthetics on $\mathrm{dp} / \mathrm{dt} \max$ with isoflurane (below) and without isoflur. ane (above) (mean \pm SE). B: bupivacaine, $\mathrm{M}$ : mepivacaine, L: lidocaine, I: isoflurane, C: control time, (I) The time when isoflur ane exposure was started, Concentration: concentration of local anesthetics, HR: heart rate. ${ }^{*} \mathrm{P}<0.05$ vs isoflurane plus lidocaine, ${ }^{* *} \mathrm{P}<0.05$ vs isoflurane plus mepivacaine.

\section{Discussion}

The contractile control system in the heart is based on the cell's ability to control $\mathrm{Ca}^{2+}$ movements. There are three major cellular sites involved in contraction: sarcolemma, sarcoplasmic reticulum and myofilaments. In the sarcolemma of the cardiac muscles, two types of $\mathrm{Ca}^{2+}$ channels have been identified: transient $(\mathrm{T})$ and long-lasting $(\mathrm{L})$ channels.

Isoflurane has been reported to inhibit both $\mathrm{L}$ type $\mathrm{Ca}^{2+}$ channels and $\mathrm{Na}^{+} / \mathrm{Ca}^{2+}$ exchange ${ }^{5,11}$, and decrease the $\mathrm{Ca}^{2+}$ store in the sarcoplasmic reticulum, decreasing the release of $\mathrm{Ca}^{2+}$ in the rat heart ${ }^{14}$ and the rabbit heart ${ }^{9}$. Also, local anesthetics, as the $\mathrm{Na}^{+}$channel blocker, decrease the inward $\mathrm{Ca}^{2+}$ current mediated by the mechanism of $\mathrm{Na}^{+} / \mathrm{Ca}^{2+}$ exchange ${ }^{15,16}$, and those such as bupivcaine and lidocaine also decrease $\mathrm{Ca}^{2+}$ release from the sarcoplasmic reticulum directly ${ }^{3.17}$, so that the myocardial contraction is depressed. Actually, in the present study, $1 \mathrm{MAC}$ isoflurane reduced myocardial contractility by $12.3 \%$ [from $4066 \pm 274(\mathrm{mmHg}$ / sec) to $3566 \pm 349(\mathrm{mmHg} / \mathrm{sec})]$, and three local anesthetics dose-dependently depressed myocardial
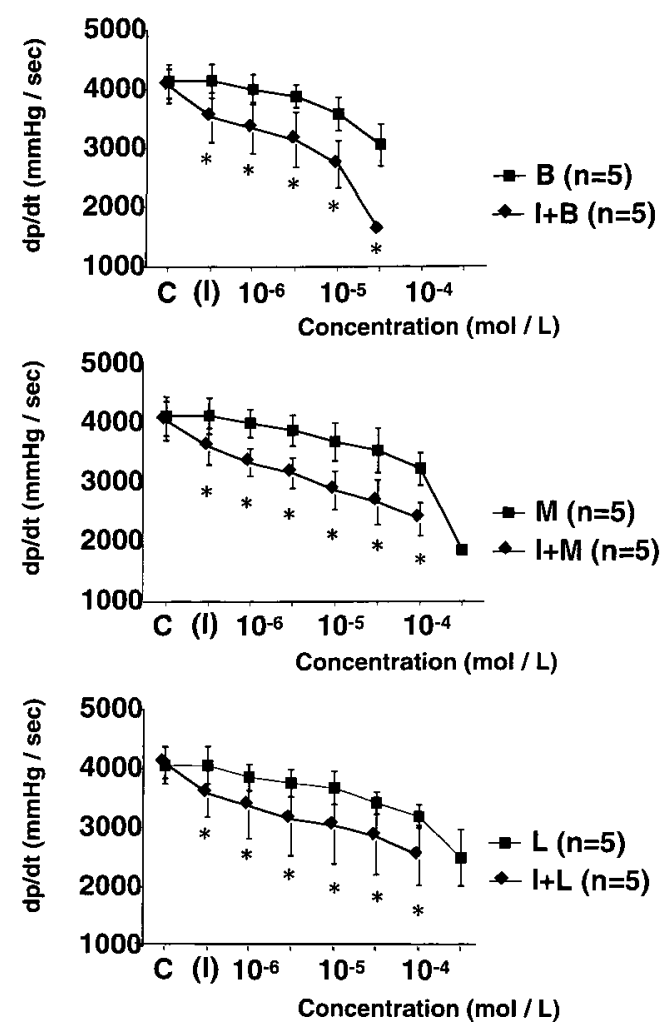

Fig. 4 Comparison among the local anesthetic groups with and without isoflurane: bupivacaine (above), mepivacaine (middle), lidocaine (below) (mean $\pm \mathrm{SE}$ ). B: bupivacaine, $\mathrm{M}$ : mepivacaine, L: lidocaine, I: isoflurance, C: control time, (I) The time when isoflurane exposure was started, Concentration: concentration of local anesthetics, HR: heart rate. ${ }^{*} \mathrm{P}<0.05$ vs the groups without isoflurane.

contractility, expressed by $\mathrm{dp} / \mathrm{dt}$ max in the working heart preparations.

The $\mathrm{Na}^{+}$channel block effects of local anesthetics suppress the maximum velocity of the depolarization of Purkinje fibers and ventricular conduction ${ }^{18,19}$. This produces a disturbance in the myocardial depolarization-repolarization cycle, and reduces heart rate and produces reentry-type arrhythmia ${ }^{1,20}$. In this study, the three local anesthetics actually depressed the heart rate dosedependently.

Many studies have shown the relative effects on cardiac functions of bupivacaine, mepivacaine and lidocaine. Komai et $\mathrm{al}^{1}$ found that the effect of bupivacaine was 14 -fold higher than that of lidocaine in slowing the heart rate to $50 \%$ of the control, using a rat working heart preparation. Ralph et $\mathrm{al}^{2}$ reported that the reductions in heart rate, force of ventricular contraction, and cardiac 

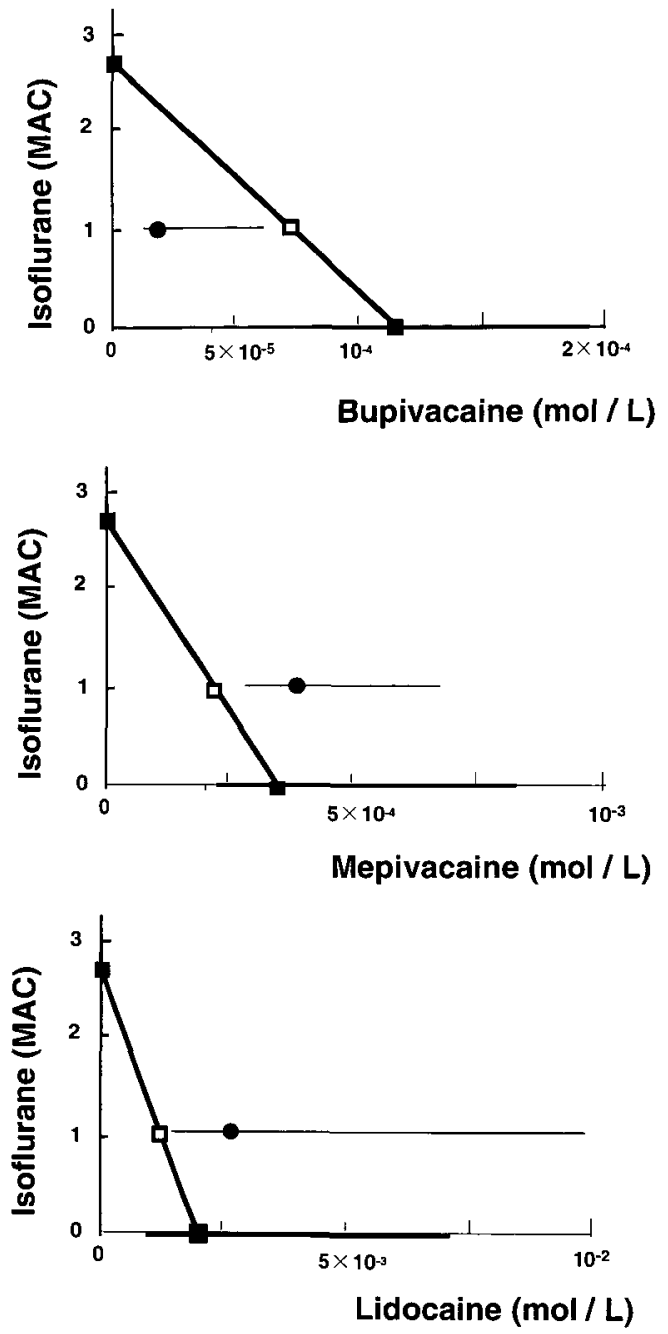

Fig. 5 Isobologram of $\mathrm{ED}_{50}$ values and $95 \%$ confidence intervals of negative inotropic effects of local anesthetic (square on the horizontal axis), isoflurane (square on the vertical axis), or the local anesthetics in combination with isoflurane (circle in the dose field). The bold lines on the axes represent the confidence interval for the single anesthetics. The diagonal line connecting the local anesthetics and isoflurane $\mathrm{ED}_{50}$ values (closed square on the axes) is the theoretical additive line, and the point on this line (open square) is the theoretical additive point. When points experimentally obtained fell below the theoretical additive line, the points indicated synergistic action on the myocardium.

output resulting from exposure to $3 \mu \mathrm{g} / \mathrm{mL}$ of bupivacaine exceeded those resulting from exposure to $30 \mu \mathrm{g} / \mathrm{mL}$ of lidocaine in the Langendorff model of guinea pigs. Kashimoto et $\mathrm{al}^{4}$ described that $25 \mu \mathrm{g} / \mathrm{mL}$ of bupivacaine in blood concentration caused the same reduction in heart rate and cardiac output as $100 \mu \mathrm{g} / \mathrm{mL}$ of lidocaine in an isolated rat lung-heart preparation.

The affinity of bupivacaine for the $\mathrm{Na}^{+}$channel is stronger than that of lidocaine, and the duration of bupivacaine to the $\mathrm{Na}^{+}$channel is longer than that of lidocaines ${ }^{3,18}$. In this study, also, bupivacaine caused cardiac arrest at lower concentrations and suppressed heart rate more than the other two drugs.

In the case of mepivacaine, it may be that the depressant force of mepivacaine is between that of bupivacaine and lidocaine, judging from the present results.

On the other hand, there was no difference in myocardial contraction among the three local anesthetics. Lynch ${ }^{3}$ reported that in isolated guinea pig right ventricular papillary muscle preparations the effects of local anesthetics, such as bupivacaine, etidocaine, and lidocaine on the depression of myocardial contractility were frequency-dependent in a reverse manner, that is, the depression of contractility was less significant at higher pacing $(2-3 \mathrm{~Hz})$ than at lower pacing $(<1 \mathrm{~Hz})$. In our study, the heart rate was relatively high because of spontaneous beats without pacing; therefore, our results may support Lynch's conclusion. On the other hand; Clakson et $\mathrm{al}^{21}$ reported that in the same preparations used by Lynch, bupivacaine and lidocaine depressed myocardial contractility in a frequencydependent manner. Anyhow, these controversial results might be due to several factors, such as the methods of these studies, the type and the situation of the preparation, and the species of animals. Actually, we did not investigate whether myocardial contractility depends on frequency or not.

In the present study the combination of the volatile anesthetic isoflurane and local anesthetics produced a negative inotropic action on the isolated perfused myocardium. The effect was synergistic with bupivacaine and additive with lidocaine or mepivacaine. It is suggested that bupivacaine at high concentrations, as well as isoflurane, has a direct effect on the L-type $\mathrm{Ca}^{2+}$ channel ${ }^{22-24}$; therefore a combination of isoflurane and bupivacaine produces a stronger suppression of myocardial contractility. Our results showed that cardiac standstill due to local anesthetics was enhanced by isoflurane in the following order: lidocaine, mepivacaine, bupivacaine. The difference in potency 
suggests that the sites involved in myocardial contraction vary among the three local anesthetics. To make the mechanisms clear, it is necessary that the process of the interactions between isoflurane and each local anesthetic is elucidated in detail, especially the intracellular $\mathrm{Ca}^{2+}$ mobilization mechanisms.

In the present study, we used a rat working heart preparation, which is a denervated heart preparation; consequently the results derived from this preparation are not affected by the autonomic nervous system, and are not necessarily directly applicable to the clinical situation. However, combinations of these commonly utilized local and inhalational anesthetics might produce a profound depressant effect on myocardial contractility.

In conclusion, the combination of the volatile anesthetic isoflurane and local anesthetics showed a negative inotropic action in a rat working heart preparation. The effect was synergistic with bupivacaine and additive with lidocaine or mepivacaine.

\section{References}

1. Komai H, Ben FR: Effects of bupivacaine and lidocaine on AV conduction in the isolated rat heart: modification by hyperkalemia. Anesthesiology 1981; 55: 281-285.

2. Ralph DT, Tammy H, Robert WL, Charles AF: Comparative cardiotoxicity of bupivacaine and lidocaine in the isolated perfused mammalian heart. Anesth Analg 1984; 63: 549-549.

3. Lynch CIII: Depression of myocardial contractility in vitro by bupivacaine, etidocaine, and lidocaine. Anesth Analg 1986; 65: 551-559.

4. Kashimoto S, Kume M, Kumazawa T: Functional and metabolic effects of bupivacaine and lignocaine in the rat heart-lung preparation. Br J Anesth 1990; 65: 521-526.

5. Gallenberg LA, Stowe DF, Marijic J, Kanpine JP, Boznjak ZJ: Depression of atrial rate, atrioventricular nodal conduction, and cardiac contraction by diltiazem and volatil anesthetics in isolated hearts. Anesthsiology 1991; 74: 519-530.

6. Drenger B, Quigg M, Blanck TJJ: Volatile anesthetics depress calcium channel blocker binding to bovine cardiac sarcolemma. Anesthesiology 1991; 74: $155-165$.

7. Nakao S, Hirata H, Kagawa Y: Effects of volatile anesthetics on cardiac calcium channels. Acta Anaesthesiol Scand 1989; 33: 326-330.

8. Fabiato A: Calcium induced release of calcium from the cardiac sarcoplasmic reticulum. Am J Physiol 1983; 245: C 1-C 14.
9. Su JY, Kerrick WGL: Effects of halothane on caffeine-induced tension transients in functionally skinned myocardial fibers. Pflugers Arch 1979; 380: 29-34.

10. Nelsone TE, Sweo T: $\mathrm{Ca}^{2+}$ uptake and $\mathrm{Ca}^{2+}$ rellease by skeletal muscle sarcoplasmic reticulum: Differing sensitivity to inhalational anesthetics. Anesthesiology 1988; 69: 571-577.

11. Robert AH, Atilla BG: Inhibition of sodium/calcium exchange and calcium channels of heart cells by volatile anesthetics. Anesthesiology 1995; 82: 1255-1265.

12. Morgan HE, Chua BHL, Fuller EO, Siehl D: Regulation of protein synthesis and degradation during in vitro cardiac work. Am J Physiol 1980; 238: 431-442.

13. Tallarida RH, Porreca F, Cowan A: Statical analysis of drug-drug and site-site interactions with isobolograms. Life Sci 1989; 45: 947-961.

14. Katuoka M, Ohnishi ST: Inhalation anaesthetics decrease calcium content of cardiac sarcoplasmic reticulun. Br J Anaesth 1989; 62: 669-673.

15. Eisner DA, Lederer WJ, Sheu SS: The role of intracellular sodium activity in sheep purkinje fibres. J Physiol 1983; 340: 239-257.

16. Daut J: The role of intracellular sodium ions in the regulation of cardiac contractility. J Mol Cell Cardiol 1982; 14: 189-192.

17. Herbette L, Messineo F, Katz AM: The interaction of drugs with the sarcoplasmic reticulum. Ann Rev Pharmacol Toxicol 1982; 22: 413-434.

18. Clarkson CW, Hondeghem LM: Mechanism for bupivacaine depression of cardiac conduction: Fast block of sodium channels during the action potential with slow recovery from block during diastole. Anesthesiology 1985; 62: 396-405.

19. Moller RA, Covino BG: Cardiac electrophysiologic effects of lidocaine and bupivacaine. Anesth Analg 1988; 67: 107-114.

20. Wheeler DM, Bardley EL, Woods WT: The electrophysiologic actions of lidocaine and bupivacaine in the isolated, perfused canine heart. Anesthesiology 1988; 68: 201-212.

21. Clarkson CW, Hondeghem LM: Evidence for specific site for lidocaine, quinidine, and bupivacaine associated with cardiac sodium channels in guinea pig ventricular myocardium. Circ Res 1985; 56: 496.

22. Coyle DE, Sperelakis N: Bupivacaine and lidocaine blockade of calcium-mediated slow action potentials in guineapig ventricular muscle. J Pharm Exp Ther 1987; 242: 1001-1005.

23. Victory JGG, Terrar DA: Effects of bupivacaine on inward currents and contraction in single myocytes isolated from guinea pig ventricle. $\mathrm{Br} \mathrm{J}$ Anaesth 1989; 62: 227-228.

24 de La Coussaye JE, Masse C, Bassoul BP, Eledjam JJ, Gagnol JP, Sassine A: Bupivacaine-induced slow-inward current inhibition. Can J Anaesth 1990; 37: $819-822$.

(Received, December 4, 1996)

(Accepted for publication, January 8, 1997) 